\title{
Cockroach Associated Foodborne Pathogens: Distribution and Antibiogram
}

\author{
Naher $\mathrm{A}^{1^{*}}$, Afroz $\mathrm{S}^{2}$, Hamid $\mathrm{S}^{1}$ \\ ${ }^{1}$ National Institute of Preventive and Social Medicine, Dhaka, Bangladesh \\ ${ }^{2}$ Sir Salimullah Medical College, Dhaka, Bangladesh
}

\begin{abstract}
Cockroaches are among the most common pests in public dwellings and health facilities. Owing to their close association with man and all his surroundings they are considered aspotential carrier and transmitter of human diseases. In hospital, cockroaches are the possible vector of nosocomial infection, specially for the transmission of drug resistant bacteria. The aim of the present study was to identify the major cockroach species, to isolate common foodborne pathogens from cockroach and to determine the antibiotic susceptibility pattern of isolated bacteria. This case control study was conducted on cockroaches captured from hospital, restaurants and houses in Dhaka city, from a period of July to December 2014. A total of 450 cockroaches were collected. Among these 300 cockroaches (150 from hospital and 150 from restaurants) were considered as case and 150 cockroaches from houses were enrolled as control group. All (100\%) cockroaches were identified as Blattellagermanica. Examination of external surface and gut homogenates showed that all (100\%) cockroaches carried bacteria, while carriage rate of fungi and parasites were $28.2 \%$ and 3.7\% respectively. Of 1901 isolated bacteria, Escherichia coli (15.3\%), Pseudomonas aeruginosa (14.4\%) and Salmonella spp. (12.9\%) were the predominant bacteria. Other bacteria of medical relevance included, Shigella spp. (6.4\%), Klebsiella spp. (8.8\%), Proteus spp. (9.6\%) and Staphylococcus aureus (4.3\%). Antibiotic resistance pattern showed high resistance rate (62.4\%) of bacterial isolates to different antibiotics. Additionally, 1051(55.3\%) of the isolates were multi drug resistant (MDR) strains, which were resistant to 5-14 antibiotics. The findings of this study revealed that cockroaches are potential source of pathogenic microorganisms including multi drug resistant bacterial strains, which could be a major threat to public health. Hence, effective preventive and control measures are required to minimize cockroach related infections.
\end{abstract}

Keywords: Cockroach, Foodborne pathogen, Antibiogram, Nosocomial infection

\section{Introduction}

Cockroaches are among the most notorious pests of premises, and they are distributed throughout the world. About 4000 cockroach species have been identified, thirty of these species are adapted to human habitation or synantropic. Of these Blattellagermaniaca, Periplanetaamericana and Blattaorientalis are considered the most common pests to human. ${ }^{1}$ Cockroach not only contaminate food by leaving droppings that can cause food poisoning, but they also transmit bacteria, protozoa, fungi and other pathogenic microorganisms in infested areas., ${ }^{2,3}$ Cockroaches feed indiscriminately on garbage, sewage, sanitary waste as well as on variety of food staffs and so have copious opportunity to disseminate human pathogens. ${ }^{4,5}$ Their filthy behaviour coupled with nocturnal life style make them ideal carrier for a wide range of pathogenic microorganisms. ${ }^{6}$ So far numerous pathogenic bacteria, including Salmonella spp, Shigella spp, Campylobacter spp, Pseudomonas aeruginosa and K. pneumoniae have been isolated from cockroaches.Different bacteria universally associated with these insects have been recognized to cause diarrhea, dysentery and food poisoning in human. Shigella dysenteriae, Salmonella typhi and toxigenic strains of Escherichia coli can be retained in the gut of cockroaches for several days. Thus, they also play a role in transmitting other foodborne diseases. ${ }^{1}$ In addition some parasites and fungi have been found in external surfaces or internal parts of body of cockroaches. $^{7,8}$

Cockroaches are one of the most significant and offensive pests found in apartments, homes, food handling establishments, hospitals, and health care 
facilitiesworldwide. ${ }^{9}$ In fact, they live in most human habitations, specially where food is stored, processed, prepared or served. So, they are commonly found in food handling establishments, where they can transmit pathogens to food, eating utensils, kitchen surfaces and other areas in their vicinity. Thus, they can be a source of infection to large number of people related to these facilities. ${ }^{5,10}$

Since the hospital environments provide them with suitable temperature, humidity and a ready source of food, presence of cockroaches there is not uncommon. Cockroaches have been detected around hospitals,sick rooms, wards, intensive care units and surgical sections. Indeed cockroaches are potential vectors of pathogenic organisms in the hospital environment. ${ }^{11}$ It was reported that $98 \%$ of cockroaches found in medical facilities could carry pathogens on their integuments or digestive tracts. ${ }^{12}$ In addition, cockroaches collected in hospitals and households have been found to harbour multidrug resistant (MDR) bacteria such as drug resistant Escherichia coli, Pseudomonas aeruginosa, Klebsiellapneumoniae and many other. Hospital cockroaches with drug-resistant bacteria have been suggested to play a role in the epidemiology of nosocomial infections. ${ }^{5,8}$ Furthermore, a neonatal unit infested with cockroaches suffered an outbreak of disease due to extended spectrum beta lactamase (ESBL) producing Klebsiella pneumoniae. ${ }^{4}$

Even though cockroaches are medically important as they harbor many human pathogens and are associated with infectious disease, the public health importance of this vector is not well documented in the study area.

In Bangladesh, cockroaches are common pests. Tropical location and hot humid climate favours multiplication and growth of cockroach. They are abundant in all areas and play role as source of infection and dissemination of disease. There is still no systemic study in Bangladesh on the role of cockroaches as vector of microorganism and their drug resistance pattern.This study therefore was carried out to identify the major cockroach species in hospital, restaurants and houses in Dhaka city, isolate the common foodborne pathogens from cockroach and to determine the antibiotic susceptibility pattern of isolated bacteria.

\section{Materials and methods}

This case control study was conducted in selected places of Dhaka city, from July to December 2014.

An ethical approval was obtained from Ethics Committee of the Bangladesh Medical Research Council (BMRC). During this period, a total number of 450 cockroaches were collected. Among these cockroaches 300 cockroaches (150 from hospital and 150 from food restaurants) were included as case group and 150 cockroaches from houses were enrolled in control group. One hospital, two restaurants and one residential area were included in this study. The hospital namely Shahid Suhrawardy Medical College Hospital, is among the largest health institutions in the city. The restaurants represented medium level operators at Mohakhali, which is served about 300-700 customers per day. Cockroaches from residential area of Banani were collected from different parts of houses. Samples of cockroaches were collected from all study sites thrice a week for 15 weeks.

Collection of cockroach: Cockroaches were collected using sterile screw-capped $250 \mathrm{ml}$ jars and sterile hand-gloves. ${ }^{13}$ Each time 10 cockroaches were caught from each of the sampling areas; they were pooled as one sample. Only cockroaches caught whole and alive was included in the study. Identification of cockroaches was performed in accordance with Burgess. ${ }^{14}$

Processing of cockroaches: The collected cockroaches were brought to the laboratory and killed in a sterile jar using chloroform soaked cotton. The external body surfaces were washed by vortexing in $5 \mathrm{ml}$ sterile physiological saline for two minutes, and the wash were taken as external body homogenate sample. After external body washing, the cockroaches were soaked in $90 \%$ ethanol for five minutes to decontaminate their external surfaces and were dried. They were then rewashed with sterile saline to remove traces of ethanol, and the alimentary tracts were aseptically dissected out using autoclave-sterilized entomological dissecting needles under a dissecting microscope. The instruments were dipped in ethanol and flamed between dissections. 
The excised guts were then homogenisedin $5 \mathrm{ml}$ of sterile normal saline water. A total of 900 specimens consisting of 450 external body surface and 450 gut homogenates of the 450 cockroaches were analysed. For primary enrichment, $1 \mathrm{ml}$ of each homogenate were inoculated separately into 9 $\mathrm{ml}$ of buffered peptone water (BPW) media (Oxoid, UK) and were incubated at $37^{\circ} \mathrm{C}$ for $18-24$ hours. ${ }^{15}$

Isolation and identification of pathogens: For isolation of bacteria, $1 \mathrm{ml}$ of each of the external and gut homogenate samples were suspended separately into $9 \mathrm{ml}$ of sterile bottles containing BPW and a homogenous enrichment suspension was prepared in nutrient broth and incubated at $37^{\circ} \mathrm{C}$ for $18-24$ hours. These solutions were then separately inoculated on MacConkey agar, Xylose Lysine Deoxycholate agar, Mannitol Salt agar and Polymyxin-B egg yolk mannitol Bacillus cereus agar (Oxoid, UK). Rappaport-Vassilidias (RV) broth (Oxoid,UK) was also used as primary enrichment medium for identification of Salmonella and Shigella and incubated at $37^{\circ} \mathrm{C}$ for 24 hours.

The isolated colonies were identified by colonial morphology, Gram staining and a battery of biochemical tests including catalase, coagulase, oxidase, citrate utilization, indole production, urease, motility, reaction in Kligler iron agar, mannitol fermentation, gas and $\mathrm{H}_{2} \mathrm{~S}$ production. ${ }^{16}$ Serogrouping of Salmonella species was done by slide agglutination using BBL antisera. ${ }^{17}$

For isolation of fungi, Sabourauds dextrose agar and Potato dextrose agar were used. For parasitological studies, about $2 \mathrm{ml}$ of both external and gut homogenate of saline washes were dispensed into conical tubes and centrifuged at $5000 \mathrm{rpm}$ for 5 minutes. The deposits were examined using a direct wet mount preparation on clean glass slides and viewed under microscope. ${ }^{16}$

Antimicrobial susceptibility testing: Antimicrobial susceptibility testing was done on Mueller-Hinton agar plates following the standardized disk diffusion technique. Bacterial inoculum was prepared by suspending the freshly grown bacteria in $5 \mathrm{ml}$ sterile nutrient broth and the turbidity was adjusted to that of 0.5 McFarland standard. Susceptibility testing was performed against the following discs (Oxoid, UK): Amoxyclave (AMC), Amoxicillin (AML), Azithromycin (AZM), Amikacin (AK), Cloxacillin(OB), CoTrimoxazole (SXT), Cefalexin (CL), Cefuroxime (CXM), Cefradine (CE), Ceftazidime (CAZ), Ceftriaxone (CRO), Ciprofloxacin (CIP), Tobramycin (TOB), Doxycycline (DO), Erythromycin (E), Gentamicin (CN), Imipenem (IPM), Levofloxacin (LEV), Mecillinam (MEL), Meropenem (MEM), Pefloxacin (PEF), Netilmicin (NET), Nalidixic acid (NA),Nitrofurantion (F).

After overnight incubation, the diameter of the zone of inhibition around the disc was measured. Interpretation of readings as sensitive, intermediate or resistant was made according to a chart. ${ }^{18}$ Intermediate readings were few and therefore considered as sensitive for the purpose of assessing the data.

Quality control: Culture media were tested for sterility and performance. Standard strains of $E$. coli ATCC 25922and S. aureus ATCC 25923 were used during culture and antimicrobial susceptibility testing.

Statistical analysis: Data were analyzed with SPSS version 20 statistical software by the MannWhitney test for quantitative data, and by chi square test or Fisher exact test for qualitative data. Comparisons of isolation rates and drug resistance between collection sites and body parts were made using Student's t-test. Level of significance was set at the $p<0.05$ level.

\section{Results}

Table I: Pathogens isolated from cockroaches collected from hospitals, restaurants and houses $(n=450)$

\begin{tabular}{lllllll}
\hline Pathogens & \multicolumn{2}{l}{ Hospitals (150) } & \multicolumn{2}{l}{ Restaurants(150) } & \multicolumn{2}{l}{ Houses (150) } \\
& No & $(\%)$ & No & $(\%)$ & No & $(\%)$ \\
\hline Fungus & 80 & 53.3 & 40 & 26.7 & 07 & 4.7 \\
Bacteria & 150 & 100 & 150 & 100 & 150 & 100 \\
Parasites & 15 & 10 & 02 & 1.3 & 00 & 00 \\
\hline Total & $230 *$ & & 112 & 74.7 & 52 & 34.7 \\
\hline *Total number and percentage increased due & to multiple \\
responses.
\end{tabular}

A total of 450 cockroaches were collected from different sources in this study. All cockroaches were identified as German cockroach, Blattellagermanica. Different pathogenic microorganisms were isolated from cockroaches captured from hospital, restaurants and houses. 
Fungi were isolated from cockroaches at hospitals $(53.3 \%)$, restaurants $(26.7 \%)$ and also from control group i.e. houses $(4.7 \%)$. Isolation of fungi, was highly significant among cases in comparison to the control group $(p<0.001)$. Bacteria were isolated from all (100\%) cockroaches in case and control group. Parasites isolated from hospitals $(10 \%)$ was highly significant $(p<0.001)$ in comparison to restaurants(1.3\%).Among total bacterial isolates, 13 bacterial species were obtained from hospital and restaurant, while 11 bacterial species were obtained from houses.
Streptococcus pyogenes and Haemophilus spp. were not detected in houses. The total numbers and percentages of bacteria are increased due to multiple response. Four bacterial species appeared frequently in both case and control group Escherichia coli (15.3\%), Pseudomonas aeruginosa (14.4\%), Salmonella spp. (12.9\%) and Bacillus cereus (11\%). The other bacterial species identified were Shigella spp, Klebsiella spp, Proteusspp, Staphylococcus aureus, Staphylococcus epidermidis, Enterococcus faecalis, Enterobacter spp, and Haemophilusspp. (table II)

Table II: Distribution of bacterial pathogens isolated from external surface and gut of Blattelagermanica collected from hospital, restaurant and houses $(\mathrm{n}=1901)$

\begin{tabular}{|c|c|c|c|c|c|c|c|}
\hline \multirow[t]{2}{*}{ Bacteria } & \multicolumn{2}{|c|}{ Hospital } & \multicolumn{2}{|c|}{ Restaurant } & \multicolumn{2}{|c|}{ House } & \multirow[t]{2}{*}{ Total $\mathrm{n}(\%)$} \\
\hline & $\begin{array}{l}\text { External } \\
\text { surface } \mathrm{n}(\%)\end{array}$ & Gut n(\%) & $\begin{array}{l}\text { External } \\
\text { surface } \mathrm{n}(\%)\end{array}$ & Gut n(\%) & $\begin{array}{l}\text { External } \\
\text { surface } \mathrm{n}(\%)\end{array}$ & $\begin{array}{c}\text { Gut } \\
\mathrm{N}(\%)\end{array}$ & \\
\hline Salmonella spp. & $66(10.1)$ & $60(11.9)$ & $43(13.5)$ & $35(15.8)$ & $22(18.0)$ & $20(25.9)$ & $246(12.9)$ \\
\hline Shigella spp. & $38(5.8)$ & $32(6.3)$ & $26(8.2)$ & $16(7.2)$ & $06(4.9)$ & $04(5.2)$ & $122(6.4)$ \\
\hline Pseudomonas aeruginosa & $110(16.8)$ & 89 (17.6) & $28(8.8)$ & $24(10.8)$ & $13(10.7)$ & 09 (11.7) & $273(14.4)$ \\
\hline Klebsiella spp. & $52(7.9)$ & $43(8.5)$ & $35(10.9)$ & $11(4.9)$ & $16(13.1)$ & $10(12.9)$ & $167(8.8)$ \\
\hline Proteus spp. & $62(9.5)$ & $52(10.3)$ & $30(9.4)$ & $20(9.0)$ & $12(9.8)$ & $07(9.1)$ & $183(9.6)$ \\
\hline Staphylococcus aureus & $24(3.7)$ & $22(4.3)$ & $14(4.4)$ & $10(4.5)$ & $08(6.6)$ & $03(3.8)$ & $81(4.3)$ \\
\hline Staphylococus epidermidis & $11(1.7)$ & $10(1.9)$ & $09(2.8)$ & $07(3.2)$ & $02(1.6)$ & $00(00)$ & $39(2.1)$ \\
\hline Bacillus cereus & $74(11.3)$ & $62(12.3)$ & $38(11.9)$ & $24(10.8)$ & $10(8.2)$ & $02(2.6)$ & $210(11.0)$ \\
\hline Enterobacter spp. & $28(4.3)$ & $32(6.3)$ & $20(6.3)$ & $24(10.8)$ & $06(4.9)$ & 03 (3.9) & $113(5.9)$ \\
\hline Enterococcus faecalis & $44(6.7)$ & $20(3.9)$ & $18(5.6)$ & $16(7.2)$ & $07(5.7)$ & $04(5.2)$ & $109(5.7)$ \\
\hline Escherichia coli & $102(15.6)$ & $70(15.6)$ & $50(15.7)$ & $34(15.3)$ & $20(16.4)$ & $15(19.5)$ & 291(15.3) \\
\hline Streptococcus pyogenes & $38(5.8)$ & $12(2.4)$ & $07(2.2)$ & $01(0.3)$ & $00(00)$ & $00(00)$ & $58(3.1)$ \\
\hline Haemophilus spp. & $06(0.9)$ & $02(0.4)$ & $01(0.3)$ & $00(00)$ & $00(00)$ & $00(00)$ & $09(0.4)$ \\
\hline Total Isolates & $655(100)$ & $506(100)$ & $319(100)$ & $222(100)$ & $122(100)$ & $77(100)$ & $1901(100)$ \\
\hline
\end{tabular}

There was significant diffenence in distribution of bacteria isolated from case and control group ( $p<0.001)$. Out of 1901 isolates, 1096 (57.7\%) were from external surface and $805(42.3 \%)$ were from gut. There was no significant difference between body parts of cockroaches and frequency of bacterial isolates.
Antimicrobial susceptibility pattern of all bacterial isolates demonstrated that resistanceto antibiotic was high for Shigella spp. (75.4\%), Salmonella spp. (73.2\%), Pseudomonas aeruginosa (71.4\%) and S. aureus (74.1\%). While Klebsiella spp. (31.1\%), E. coli (43.6\%) and Haemophilusspp (44\%) showed lower resistance rate (table III). 
Table III: Antibiotic susceptibility pattern of the bacteria isolated from Blattelagermanica $(\mathrm{n}=1901)$

\begin{tabular}{|c|c|c|c|}
\hline Bacteria & $\begin{array}{c}\text { Total number of } \\
\text { bacteria }\end{array}$ & $\begin{array}{l}\text { Antibiotic Sensitive } \\
\mathrm{n}(\%)\end{array}$ & $\begin{array}{l}\text { Antibiotic } \\
\text { Resistance } \\
\mathrm{n}(\%)\end{array}$ \\
\hline Salmonella spp. & 246 & $66(26.8)$ & $180(73.2)$ \\
\hline Shigella spp. & 122 & $30(24.6)$ & $92(75.4)$ \\
\hline Pseudomonas aeruginosa & 273 & $78(28.6)$ & $195(71.4)$ \\
\hline Klebsiella spp. & 167 & $115(68.9)$ & $52(31.1)$ \\
\hline Proteus spp. & 183 & $61(33.3)$ & $122(66.7)$ \\
\hline Staphylococcus aureus & 81 & $21(25.9)$ & $60(74.1)$ \\
\hline Staphylococcus epidermidis & 39 & $17(43.6)$ & $22(56.4)$ \\
\hline Bacillus cereus & 210 & $40(19)$ & $170(81)$ \\
\hline Enterobacter spp. & 113 & $41(36.3)$ & $72(63.7)$ \\
\hline Enterococcus faecalis & 109 & $53(48.6)$ & $56(51.4)$ \\
\hline Escherichia coli & 291 & $164(56.4)$ & $127(43.6)$ \\
\hline Streptococcus pyogenes & 58 & $24(41.4)$ & $34(58.6)$ \\
\hline Haemophilus spp. & 09 & $5(56)$ & $4(44)$ \\
\hline Total & 1901 & $715(37.6)$ & $1186(62.4)$ \\
\hline
\end{tabular}

Multiple resistance pattern among bacterial isolates has been demonstrated.

Table IV: Frequency of multiple resistance pattern among various bacteria isolated from Blattelagermanica $(\mathrm{n}=1051)$

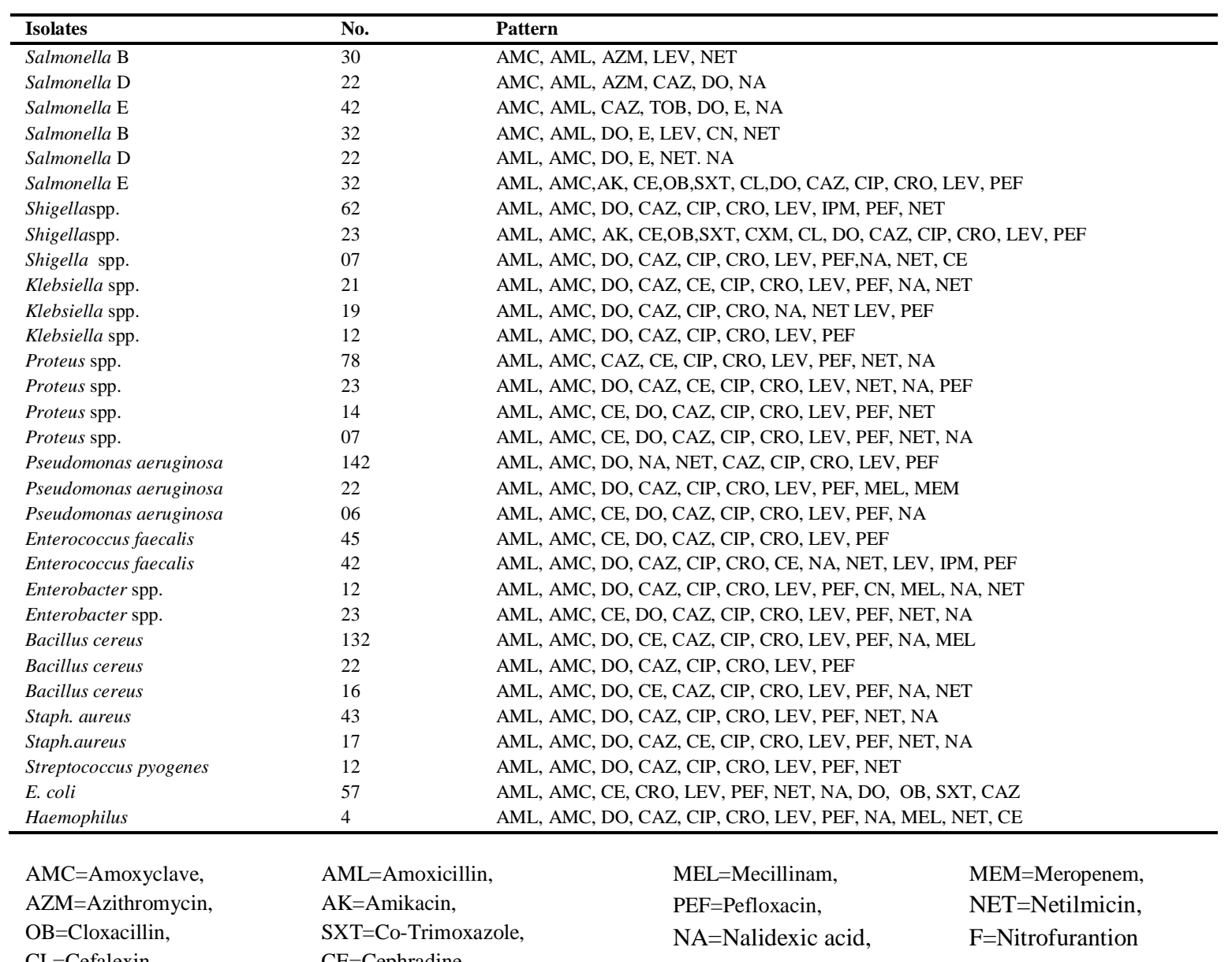

$\mathrm{CXM}=$ Cefuroxime,

$\mathrm{CRO}=$ Ceftriaxone,

TOB=Tobramycin

$\mathrm{E}=$ Erythromycin,

IPM=Imipenem,
$\mathrm{CAZ}=$ Ceftazidime

$\mathrm{CIP}=$ Ciprofloxacin,

$\mathrm{DO}=$ Doxycycline,

$\mathrm{CN}=$ Gentamicin,

LEV=Levofloxacin,
Fifteen different multiple resistance pattern were seen, ranging from 5-14 drugs. Multiple resistance was high for Shigella spp. where 23 (25\%) isolates were resistant to14 drugs, $57(19.6 \%)$ isolates of 
E.coli were resistant to 13 antibiotics. All Salmonella isolates showed four patterns of multiple resistance. Majority of them were resistant to at least 5 drugs, but Salmonella E serogroup was resistant to 13 drugs. Multiple resistance pattern of 10-11 drugs was common among most (55.3\%) of other bacterial isolates.

\section{Discussion}

Cockroaches are common in many human habitations, particularly in places where food is stored, processed or preserved. Apart from that they are also frequently detected in hospital environment. ${ }^{19}$ Indeed cockroaches are found everywhere, and possess nocturnal and omnivorous characteristics, which make them ideal carrier for microorganisms. Cockroaches are the main source of bacterial pathogens and they are also associated with multiple drug resistant strains. Therefore they have a great impact on spread of diseases and dispersal of multi drug resistant bacterial strains. ${ }^{20}$

All cockroaches collected in this study were identified as Blattellagermanica. This species was frequently found in all areas of hospital, restaurants and houses included in the present study. This finding is supported by other studies. ${ }^{19,31,32}$ Blattellagermanica are the most abundant and closely associated with humans worldwide. They are the most common and predominant cosmopolitan pest in the world due to change in human travel, commerce and urban environment. $^{21}$ Furthermore preference of Blattellagermanica to inhabit in tropical and subtropical weather, might make Dhaka city suitable habitat for this cockroach species. In contrary to the findings of the study, other studies reported Periplanetaamericana as the common cockroach species. This might be due to difference in method of capturing cockroaches or due to environmental variation.

In this study, a variety of microbial flora including bacteria, parasites and fungi were isolated. Such observation has also been reported by other researchers ${ }^{22,23,31}$ A wide range of bacterial species, including Escherichia coli, Klebsiella spp, Salmonella spp, Pseudomonas aeruginosa, Shigella spp, Staphylococcus aureus, Proteus spp,and other bacteria were isolated in this study. Most of these organisms have also been isolated from cockroaches in different countries worldwide. ${ }^{14,23,24}$ This suggests that the type of bacterial flora carried by cockroaches may be independent of geographical location or socioeconomic factors. The predominant bacteria isolated were E.coli (15.3\%) followed by Pseudomonas aeruginosa (14.4\%). This finding is analogous with a report from Iran. ${ }^{25}$ However, in contrary Hamid et al reported Klebsiella spp. as predominant organism in his study. ${ }^{26}$ The isolation of such wide variety of bacteria from cockroaches indicate that house hold pests could be a health challenge to human. This finding also shows the potential role of these insects in distributing and spreading pathogens in human communities. Some of the isolated bacteria are known to be pathogenic while others are opprtunistic pathogens or conaminants which play role in food spoilage. The isolation of E.coli from cockroaches point out that, these insects have been in contact with human feces or feces contaminated material. This shows the risk of transmission of other bacteria present in feces to human. In addition isolation of Salmonella from these insects especially in those from restaurants is of concern. It may be source of infection for a group of people related to these institutions and lead to an outbreak of enteric fever. The bacterial species most frequently isolated were gram negative bacilli, explicitly in the family entrobacteriaceae. It is known that, cockroaches are considered as an ecological niche of some members of this family. ${ }^{1}$ This isolates are the main causes of a diverse type of community acquired and nosocomial infections, notably urinary tract infections, wound infections, respiratory tract infections, gastroenteritis, septicemia, pneumonia, biliary and peritoneal infections. ${ }^{33}$

The isolation of higher rate $(57.7 \%)$ of bacterial isolates from the external surface compared to gut $(42.3 \%)$ of cockroach is consistent with other studies. $^{28,29}$ Tachbele et al and Ejimadu et al reported higher isolation of bacteria from gut of cockroach rather than from external surface. ${ }^{19,34}$ The relative high external surface carriage rate may be related to filthy habit of cockroach, they crawl and move on different 
sanitary waste, gurbage and carry different microorganisms on their surface.

In the present study, number of bacterial isolates from cockroaches collected in hospital were significantly higher than those from domestic cockroaches. Observation of this study goes in agreement with other studies..$^{5,19,30}$ Hospital environment may be more conductive to acquiring bacteria from many different contaminated sources such as water, food, garbage, hospital waste. This may account for high isolation rate of bacteria in hospital.

Antibiotic resistance pattern of isolates was also explored in this study. It was surprising that high resistance rate (41-81\%) were observed against different antibiotics used. This is consistent with other studies. ${ }^{19,33}$ Among antibiotic tested, all isolates were resistant to amoxycillin and amoxyclave, while more than half of isolates were resistant to doxycycline, nalidixic acid, ceftazidime, ciprofloxacin and ceftriaxone. However, imipenem and meropenem were relatively most effective antibiotic against the bacterial isolates. Almost similar resistant rate was also reported by Moges et al from Ethiopia, but in his study, isolates were mostly sensitive to ciprofloxacin. $^{33}$ Such high antibiotic resistance, even though antibiotics are not applied on cockroaches, is astonishing, but it is known that high resistance rate are reported among pathogens associated with foods. In fact, a close association between cockroaches and food could be the probable reason for isolation of resistant strains of bacteria from cockroach.

In addition, multiple drug resistance patterns have been demonstrated in isolated bacteria. About 55\% of isolates were found to be multi drug resistant strain. These strains were resistant to 5-14 antibitiotics. Similar findings were reported by Tachbele et al. ${ }^{19}$ In this study, samples included cockroaches from hospitals, where multi drug resistant strains are common and widespread. This may be the reason for high rate of MDR strains isolated in this study.

Since cockroaches are found to be potential source of pathogenic microorganisms and multi drug resistant bacterial strains, therefore appropriate preventive and control measures can reduce cockroach associated infection both in community and hospital settings.

\section{Conclusion}

The present study documented a high microbial load and multi drug resistant bacteria, specially for the commonly used antibiotics such as amoxicillin, amoxycave, doxacyline, and ciprofloxacin. The organisms carried and harboured by cockroaches are also important nosocomial agentsand may play a role in transmission and spread of nosocomial infections. Therefore, appropriate preventive and control measures through effective and integrated pest control system is urgently needed to reduce cockroach associated infections. Preventive measures such as increasing awareness about danger of pathogen transmission by cockroach, encouraging people to keep human dwelling clean, regular emptying and proper disposal of garbage, using insecticides into hiding places of domestic pests will reduce cockroach load and hence cockroach borne illness in the locality.

\section{Acknowledgement}

We express gratitude and thanks to Bangladesh Medical Research Council (BMRC) for funding to conduct the study.

\section{Reference}

1. Kassiri H, Kasiri A, Quaderi A. Detection and Prevalence Rate of American Cockroaches (Periplanetaamericana) Bacterial Infections in Human Dwellings. Arch Clin Infect Dis.2014;9:1-3

2. Rueger MA, Olson TA.Cockroaches (Blattaria) as vectors of food poisoning and foodinfection organisms. J Med Entomol. 1969;6:185-89.

3. Czajka E,Pancer K,Kochman M et al. Characteristics of bacteria isolated from body surface of German cockroaches caught in hospitals. Przegl Epidemiol. 2003; 57:655-62.

4. Cotton MF, Wasserman E, Pieper CH, Van Tubbergh D, Campbell G, Fang FC, Barnes J. Invasive disease due to extended spectrum beta-lactamase-producing Klebsiella pneumoniaein a neonatal unit: the possible role of cockroadhes. J Hosp Infect. 2000; 44: 13-17.

5. Pai HH, Chen WC, Peng CF. Isolation of bacteria with antibiotic resistance from household cockroaches 
(Periplanetaamericana and Blattellagermanica). Acta Trop. 2005; 93: 259-65.

6. Graczyk TK, Knight R, Tamang L.Mechanical transmissionof human protozoan parasites by insects. Clin Microbiol Rev. 2005;18: 128-32.

7. Thyssen PJ, Moretti T, Ueta MT, Ribeiro OB. The role of insects (Blattodea, Diptera, and Hymenoptera) as possible mechanical vectors of helminths in the domiciliary and peridomiciliary environment. Cad Saude Publica. 2004; 20:1096-1102.

8. Fotedar R, Banerjee U. Nosocomial fungal infectionsstudy of the possible role of cockroaches (Blattellagermanica) as vectors. Acta Trop.1992; 50:339-43.

9. Bonnefoy X, Kampen H, Sweeney K. Public Health Significance of Urban Pests. World Health Organization. Geneva, Switzerland. 2008.

10. Jeffery J, Sulaiman S, Oothuman P, Vellayan S, Zainol-Ariffin $\mathrm{P}$, Paramaswaran $\mathrm{S}$ et al. Domiciliary cockroaches found in restaurants in five zones of Kuala Lumpur Federal Territory, Peninsular Malaysia. Trop Biomed.2012;29:180-86.

11. Dubus J, Guerra M, Bodiou A. Cockroach allergy and asthma.Allergy. 2001;56:351-52.

12. Cloarec A, Rivault C, Fontaine F, Le Guyader A. Cockroaches as carriers of bacteria in multi-family dwellings. Epidemiol Infect. 1992;109:483-90.

13. Paul S, Khan AM, Muhibullah M. Evaluation of the common cockroach Periplanetaamericanaas carrier of medically important bacteria. J Commun Dis. 1992; 24: 206-10.

14. Burgess NRH. Hospital design and cockroach control. Transactions of the Royal Society ofTropical Medicine and Hygiene. 1984; 78: 293-94.

15. Fotedar R, Shriniwas UB, Verma A. Cockroaches (Blattellagermanica) as carriers ofmicroorganisms of medical importance in hospitals. Epidemiol Infect. 1991;107: 181-87.

16. Mackie TJ, McCartney JE. Laboratory Strategies in diagnosis. In Colle JG, Duguid JP, FraserAG, Marmion BP, eds, Practical Medical Microbiology, XIIIth ed. London, UK. ChurchillLivingstone. 1989; 590-624.

17. Difco Laboratories, Difco \& BBL Manual, Difco Laboratories, Detroit, Mich, USA, 1st edition, 2003.Clinical and Laboratory Standards Institute (CLSI), "Performancestandards for antimicrobialsusceptibility testing:twenty-first informational supplement," Tech. Rep. M100S21,Clinicaland Laboratory Standards Institute (CLSI), Wayne, Pa,USA. 2012.
18. Fakoorziba MR, Eghbal F, Hassanzadeh J, Moemenbellah-Fard MD. Cockroaches(Periplanetaamericanaand Blattellagermanica) as potential vectors of the pathogenicbacteria found in nosocomial infections. Ann Trop Med Parasitol. 2010;104:521-28.

19. Tachbele E, Erku W, Gebre-Michael T, Ashenafi M. Cockroach associated food bornebacterial pathogens fromsome hospitals and restaurants in Addis Ababa, Ethiopia: distributionand antibiograms. J Rur Trop Public Health. 2006; 5: 34-41.

20. Bennett GW. Cockroaches and disease. In: Capinera JL, editor. Encyclopedia of entomology.Dordrecht: Springer; 2008. p. 948-52.

21. Patience BT, Eric SD, Simon KA et al. Microbial carriage of cockroaches at a tertiary carehospital in Ghana. Environ Health Insights. 2013; 7: 59-66.

22. Clement I, Philip O, Mercy IL, Joy IE, Osesojie I. Comparative analysis of pathogenic organisms in cockroaches from different community settings in Edo state, Nigeria. Korean JParasitol. 2014; 52: 177-81.

23. Cloarec A, Rivault C, Fontaine F, Le Guyader A. Cockroaches as carriers of bacteria inmulti-family dwellings. Epidemiol Infect. 1992;109: 483-90.

24. Le Guyader A, Rivault C, Chaperon J. Microbial organisms carried by brown bandedcockroaches in relation to their spatial distribution in a hospital. Epidemiol Infect. 1989;102:485-92.

25. Feizhaddad MH, Kassiri H, Sepand MR, Ghasemi F. Bacteriological survey of American cockroaches in hospitals. Middle-East J Sci Res.2012; 12: 985-89.

26. Hamid K, Ali K, Shahnaz K. Investigation on American cockroaches medically important bacteria in Khorramshahr hospital, Iran. Asian Pac J Trop Dis. 2014; 4: 201-03.

27. Tatfeng YM, Usuanlele MU, Orukpe A et al. Mechanicaltransmission of pathogenic organisms: the role of cockroaches.JVector Borne Dis 2005;42: 12934.

28. Adeleke MA, Akatah HA, Hassan AW, Adebimpe WO. Microbial load and multiple drugresistance of pathogenic bacteria isolated from feaces and body surfaces of cockroaches in anurban area of southwestern Nigeria. JMicrobiol Biotechnol Food Sci. 2012; 1: 1448-61.

29. Fotedar R, Nayar E, Samantray JC, Shriniwas UB, Dogra V,Kumar A. Cockroaches as vectors of pathogenic bacteria. JCommun Dis. 1989;21:318-22.

30. Salehzadeh A, Tavacol P, Mahjub H. Bacterial, fungal and parasitic contamination ofcockroaches in public hospitals of Hamadan. Iran J Vector Borne Dis. 2007; 44:105-10. 
31. Solomon F, Belayneh F, Kibru G, Ali S. Vector Potential of Blattellagermanica (L.) (Dictyoptera: Blattidae) for Medically Important Bacteria at Food Handling Establishments in Jimma Town, Southwest Ethiopia. BioMed ResearchInternational 2016. Available at-http://dx.doi.org/10.11.55/2016/2825056.

32. Memona H, Manzoor F, Riaz S. Species Diversity and Distributional Pattern of Cockroaches in Lahore, Pakistan.J Arthropod-Borne Dis 2017; 11: 249-59.
33. Moges F, Eshetie S, Endris $M$ et al. Cockroaches as a Source of High Bacterial Pathogens withMultidrug Resistant Strains in Gondar Town, Ethiopia. BioMed Research International 2016. Available athttp://dx.doi.org/10.11.55/2016/3490906.

34. Ejimadu LC, Goselle ON, Ahmadu YM, James Rugu NN. Specialization of Periplaneta Americana (American Cockroach) and BlattellaGermanica (German cockroach) Towards Intestinal Parasites: A Public Health Concern. J Pharm Biol Sci 2015; 10 : 23-32.

*Correspondence: Akhtarun Naher, Head, Department of Microbiology, Sir Salimullah Medical College, Dhaka, Bangladesh, e-mail: akhtnaher@yahoo.com 